\title{
Performance of N3 Sensitized Titania Solar Cell under Artificial Light Ambience
}

\author{
Chaitali V. Jagtap, Vishal S. Kadam, ${ }^{\#}$ Sandesh R. Jadkar and Habib M. Pathan*
}

The indoor utilization of emerging photovoltaics is promising but power conversion efficiency (PCE) under indoor lighting is still challenging. Dye sensitized solar cell (DSSC) is one of the most excellent options to harvest and convert the artificial indoor light into electricity. In present study, we investigated the indoor performance of N3 sensitized Titania DSSCs under artificial lighting. We observed a substantial improvement in PEC of solar cell.

Under the indoor illumination of $33 \mathrm{~mW} / \mathrm{cm}^{2}$, the maximum PCE obtained was $28.21 \%$. Our findings suggests that the obtained high efficiency N3 sensitized Titania DSSCs under artificial lighting have a good potential application for low power electronic devices for their autonomous operation. Graphical abstract shows the result with glowed LED using three series connected DSSCs.

Keywords: Titania; N3 dye; Dye sensitized solar cell; Artificial light; High efficient; Solar cell

Received 24 November 2018, Accepted 2 January 2019

DOI: $10.30919 / \mathrm{esee} 8 \mathrm{c} 220$

\section{Introduction}

Solar cells are the prime candidate for harvesting available indoor light, even if they have been initially developed for outdoor lighting. During the last decade, a large number of photovoltaic technologies such as c$\mathrm{Si}$, a-Si, polymer PV, CdTe, GaAs, CIGS etc. have been investigated under the full outdoor conditions. ${ }^{1-7}$ DSSC has much attention due to its low cost, easy and inexpensive fabrication, transparency, high photoconversion efficiency and long term stability. ${ }^{8}$ Many researchers examine to improve the PEC by modifying photoanodes, counter electrode, dye and electrolyte. Among them the light harvesting capacity nature of solar cell depends upon photoanode. ${ }^{9}$ The performance of these solar cell technologies depends on the variation in spectral, reflection, temperature, irradiance and power of the modules throughout the day and season. ${ }^{4}$ Therefore it is also important to know how the performance of these solar cell technologies varies with change in operating conditions including indoors than total energy produced outdoor by panels over the course of a time period. ${ }^{10,11}$ Furthermore, these technologies are based on inorganic materials which require high fabrication costs and large amount of energy. Moreover, they often use toxic and scarce materials. ${ }^{12}$ The third generation solar cells such as dye sensitized solar cells (DSSCs) have attracted considerable interest during the past two decades due to their potential as a low cost and easily processable alternative to traditional solid state solar cells. ${ }^{13}$ These

Advanced Physics Laboratory, Department of Physics, Savitribai Phule Pune University, Pune 411007

*E-mail: pathan@physics.unipune.ac.in

" Author contributes equally solar cells can be used for outdoor and indoor light harvesting and conversion of light into electricity. They showed an outstanding performance under indoor conditions with an artificial light source in comparison with other solar cell technologies. ${ }^{14}$ The unique properties of DSSCs make them the best alternative to wired and battery energy sources as they are capable of maintaining a high photovoltage even in diffuse light conditions. ${ }^{15-17}$ It has been reported that the DSSCs have larger power conversion efficiency compared to silicon under artificial illumination such as compact fluorescent lamps (CFL) and light emitting diodes (LEDs). ${ }^{18-21}$ Recently, the power conversion efficiency (PCE) with $28.9 \%$ has been reported for DSSC under ambient lighting using dual sensitizer. ${ }^{22}$

During functioning of a DSSC, when light is incident on cell, dye molecule absorbs an incident photon and gets excited to an excited state. The excited dye molecule then gets injected to the conduction band of the semiconductor. Then, by reducing redox species of I the oxidized dye molecule is regenerated and returns the dye to its ground state which allows to absorb another photon. Nanostructure semiconductor photoelectrode has large surface area for dye adsorption which enhances the solar cell performance. ${ }^{23}$

Here, we show the out performance of N3 sensitized titania DSSC under the indoor lighting. The indoor light harvesting is a nascent technology and hence no standard light illuminations source or testing procedure has yet been established. Our results highlight the PEC value of $28.2 \%$ using N3 dye with $4 \mathrm{~mA} / \mathrm{cm}^{2}$ of anodic spike i.e $\mathrm{I}_{\mathrm{d}}$. Therefore this study is useful for understanding the possible outcomes of solar cell under artificial lightning. Typically, the light intensity under indoor lighting is less and the optical spectrum is completely different compared to outdoor conditions. The optical spectrum for indoor 
lighting is primarily restricted in a narrow spectral band in the visible region. For indoor light, we have compared xenon lamp illumination in solar simulator and commercial white LED lamp illumination having intensities $50 \mathrm{~mW} / \mathrm{cm}^{2}$ and $33 \mathrm{~mW} / \mathrm{cm}^{2}$ respectively. Light intensities affect the photovoltaic performance outcomes from its influence on the cell parameter. Therefore it is important to examine the solar cell under several light illumination condition to understand the possible outcomes. Further the theoretical calculation such as electron lifetime, diffusion length, charge collection efficiency, effective electron diffusion co-efficient and effective electron diffusion length which is useful to study the electron transport properties of solar cell.

\section{Experimental Section}

\section{Fabrication of Photoelectrode}

For fabrication of $\mathrm{TiO}_{2}$ paste, commercial $0.5 \mathrm{~g} \mathrm{TiO}_{2}$ nano-particles $(\mathrm{P} 25$ degussa, Nanoshel LLC, US) were mixed with $2 \mathrm{ml}$ ethanol (Changshu, China) using homogenizer in small glass vessel with subsequent addition of $0.5 \mathrm{~g}$ ethyl cellulose (SDFCL, India), $0.25 \mathrm{ml}$ terpineol anhydrous (KPS Ltd., India) and $0.25 \mathrm{ml}$ acetyl acetone (HPCL, India). Gummy slurry form after $30 \mathrm{~min}$ and this slurry sonicated using probe sonicator (QSonica-Q700, USA) for $2 \mathrm{hr}$ till no particulates are seen in the paste. Further, in preparation photoelectrode, the $\mathrm{TiO}_{2}$ films were deposited onto conducting fluorine doped tin oxide (FTO- Sigma Aldrich, USA) having sheet resistance of $15-18 \Omega / \mathrm{cm}$ glass substrate by modified doctor blade. Before fabricating $\mathrm{TiO}_{2}$ film, FTO were cleaned in ultrasonic bath by using double distilled water, acetone and ethanol subsequently for $10 \mathrm{~min}$. The FTO substrates were air dried at room temperature. After drying, the edges of the substrate were covered with $100 \mu \mathrm{m}$ transparent plastic paper to prepare the film. Then to form $\mathrm{TiO}_{2}$ film, one drop of the prepared paste was placed at the center of substrate and the edge of a microscopic slide was used to spread the paste over the substrate. The films then sintered at $450{ }^{\circ} \mathrm{C}$ for $1 \mathrm{hr}$. After sintering, thickness of $\mathrm{TiO}_{2}$ film was observed to be 15 $\mu \mathrm{m}$ from SEM cross section. The films were further dipped in $0.1 \mathrm{M}$ thioglycolic acid (Thomas Baker (Chemicals) Pvt. Ltd, India) using dip coating method for $60 \mathrm{sec}$ to itch the $\mathrm{TiO}_{2}$ film. Before solar cell testing the films were immersed in standard ruthenium based red 'cisbis(isothiocynato)bis(2,2'-bipyridyl-44'dicarboxylato)ruthenium(II)' N3 dye (Sigma Aldrich, USA) with the concentration of $0.03 \mathrm{mM}$ solution in ethanol for $90 \mathrm{~min}$ for sensitization. X-ray diffractometry (XRD) measurements were performed to further evaluate the structural properties of the $\mathrm{TiO}_{2}$ film. XRD pattern showed that prepared film were polycrystalline in nature. Supporting information, Fig. S1. Scanning electron microscopy analysis was performed to study morphology of $\mathrm{TiO}_{2}$ film structure Supporting information, Fig. S2. The sintered films were found porous signifying its suitability for DSSC applications.

\section{Solar cell Assembly}

Five layer cello-tape of thickness $\sim 45 \mu \mathrm{m}$ was used as spacers placed at the edge of $\mathrm{TiO}_{2}$ working electrode with the active area of $0.6 \times 0.3$ mm. Platinum coated FTO as a counter electrode facing the $\mathrm{TiO}_{2}$ photoelectrode was held together using binder clips on opposite end. Polyiodide solution was used as liquid electrolyte consisting of $0.5 \mathrm{M}$ of Lithium iodide (SRL, India), $0.05 \mathrm{M}$ of Iodine (Fisher Scientific, USA) and $0.15 \mathrm{M}$ tertiary butyl pyridine (ACROS Organics, Belgium) in $100 \mathrm{ml}$ Acetonitrile (SDFCL, India). Just before analysis, drops of prepared polyiodide electrolyte were induced in prepared sandwiched cell till no air bubble is present. The light was introduced such that light gets penetrate through the FTO back contact to the dye adsorbed onto the $\mathrm{TiO}_{2}$ photoelectrode.

\section{Solar cell characterization}

XRD (D/B max-2400, Rigaku, USA) was used to determine crystalline nature, phase and crystallite size of $\mathrm{TiO}_{2}$ film. The sample was placed into the diffractometer for analysis. Sample was scanned from $20^{\circ}$ to $80^{\circ} 2 \theta$ diffraction angle. Scanning electron microscopy (SEM) ( JEOLJSM 6360-A, USA) was used to study the morphology and cross section of $\mathrm{TiO}_{2}$ film. The images were obtained at various magnification of $\mathrm{x} 3000, \mathrm{x} 10,000$ and $\mathrm{x} 30,000$. UV-Vis spectrophotometer (JASCO V-670, Germany) was used to study optical absorption properties and calculation of band gap of $\mathrm{TiO}_{2}$ photoelectrodes, spectra of $\mathrm{N} 3$ dye and $\mathrm{TiO}_{2}$ sensitized N3 Dye in diffused reflectance and transmittance mode in the range $200-800 \mathrm{~nm}$ at room temperature. Photovoltaic parameters of each cell were measured using solar stimulator (Oriel Sol-2A, Newport, USA). AM1.5 sunlight filter with illumination intensities $50 \mathrm{~mW} / \mathrm{cm}^{2}$ and $33 \mathrm{~mW} / \mathrm{cm}^{2}$ LED (Nvis Clean Tech, India). Keithley source meter 2420 (Keithley instruments Ltd., USA) was used to measure J-V characteristics. The incident intensity of illuminating light sources was measured using sun meter (Solaron DSM 01, India) and digital lux meter (Lutron LX-101A, Lutron Electronic Enterprise CO., LTD., Taiwan). Optical luminescence of illuminated light source was measured using optical spectrometer (Ocean Optics HR 4000, USA). All the J-V curves of solar cell were obtained in the dark and under illumination. The J-V characteristics used to obtain open circuit voltage $\left(\mathrm{V}_{\mathrm{oc}}\right)$, short circuit current density $\left(\mathrm{J}_{\mathrm{sc}}\right)$, the maximum voltage point $\left(\mathrm{V}_{\text {max }}\right)$, the maximum current density $\left(\mathrm{J}_{\max }\right)$, maximum power $\left(\mathrm{P}_{\max }\right)$, fill factor (FF), efficiency (Eff). Photocurrent and photovoltage responses with respect to time and electrochemical impedance spectra were measured using potentiostat/galvanostat (Vertex IVIUM Technologies, Netherlands).

\section{Result And Discussion Optical study}

It is clear from Fig. 1 (a) that the spectral distribution of light energy changes with type of illumination source. Unlike xenon lamp, which has broad emission spectra similar to AM1.5G, the LED has narrow spectra mainly in the visible range. The area under curve is observed to be lower for LED lamp from 400 to $700 \mathrm{~nm}$ whereas xenon lamp absorbs the maximum wavelength from 300 to $800 \mathrm{~nm}$. As these cells will be ever useful in concentrated solar cell applications which will cause reexamination of the operating limitations which will improve efficiency at 1sun. The low charge carrier mobility results in high charge accumulation under illumination, which will in turn cause increased recombination which affects overall efficiency of cell. ${ }^{24}$ The output of any solar cell depends upon the spectral composition of incident light, its intensity and the angle at which the light is incident. The artificial light we are using has less magnitude than solar simulator and we utilized maximum light having narrow emission spectra. Thus the sources of heat affecting the photovoltaic device are minimized using indoor measurements. If we measure photoconversion efficiencies of device under different light intensities it becomes easier to study for which the device is best suited. Here in our study the drastic change in efficiency from $28 \%$ to $4 \%$ shows that the device is suitable for indoor lightning. The reason for this decrease can be due the spectral distribution and power density of the incident light. If we compare the spectral distribution in the IR region whereas LED shows spectral distribution in the visible region ${ }^{25}$ as shown in Fig. 1 (a). One more reason to have greater efficiencies is its lower power incident densities. DSC technology delivers better performance under interior lightning because it is able to sustain performance even at low incident power densities and because of the good match between emission spectra of the dye, as both of them mainly span the range of visible wavelength. ${ }^{26}$

Fig. 1 (b) shows the absorption spectra of $\mathrm{TiO}_{2}$ photoanode, $\mathrm{N} 3$ dye, $\mathrm{N} 3$ sensitized $\mathrm{TiO}_{2}$ photoanode. It is clearly observed spectra of N3 dye and sensitized $\mathrm{TiO}_{2}$ photoelectrode is extended in visible region. 

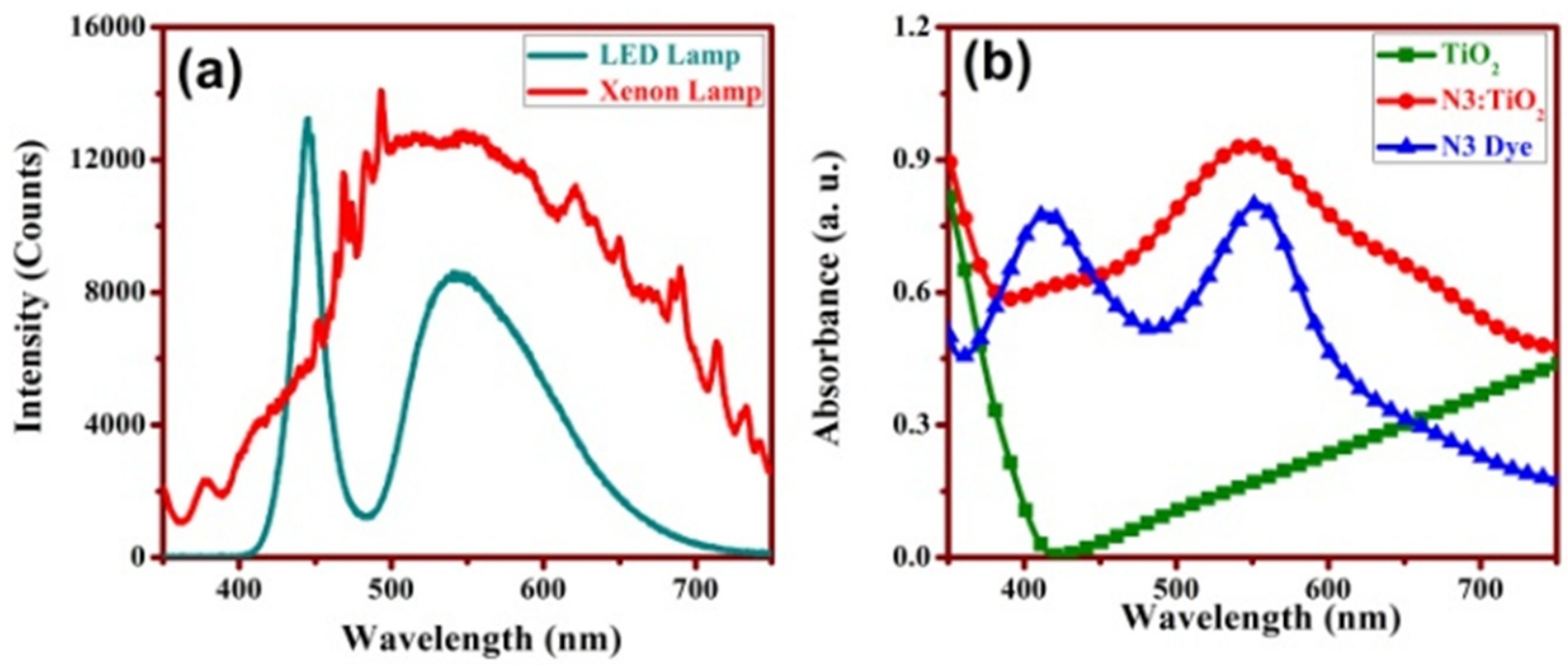

Fig. 1 (a) Emission spectra of LED lamp and xenon lamp; (b) absorption spectra of $\mathrm{TiO}_{2}, \mathrm{~N} 3$ dye and $\mathrm{N} 3 / \mathrm{TiO}_{2}$ photoanode.

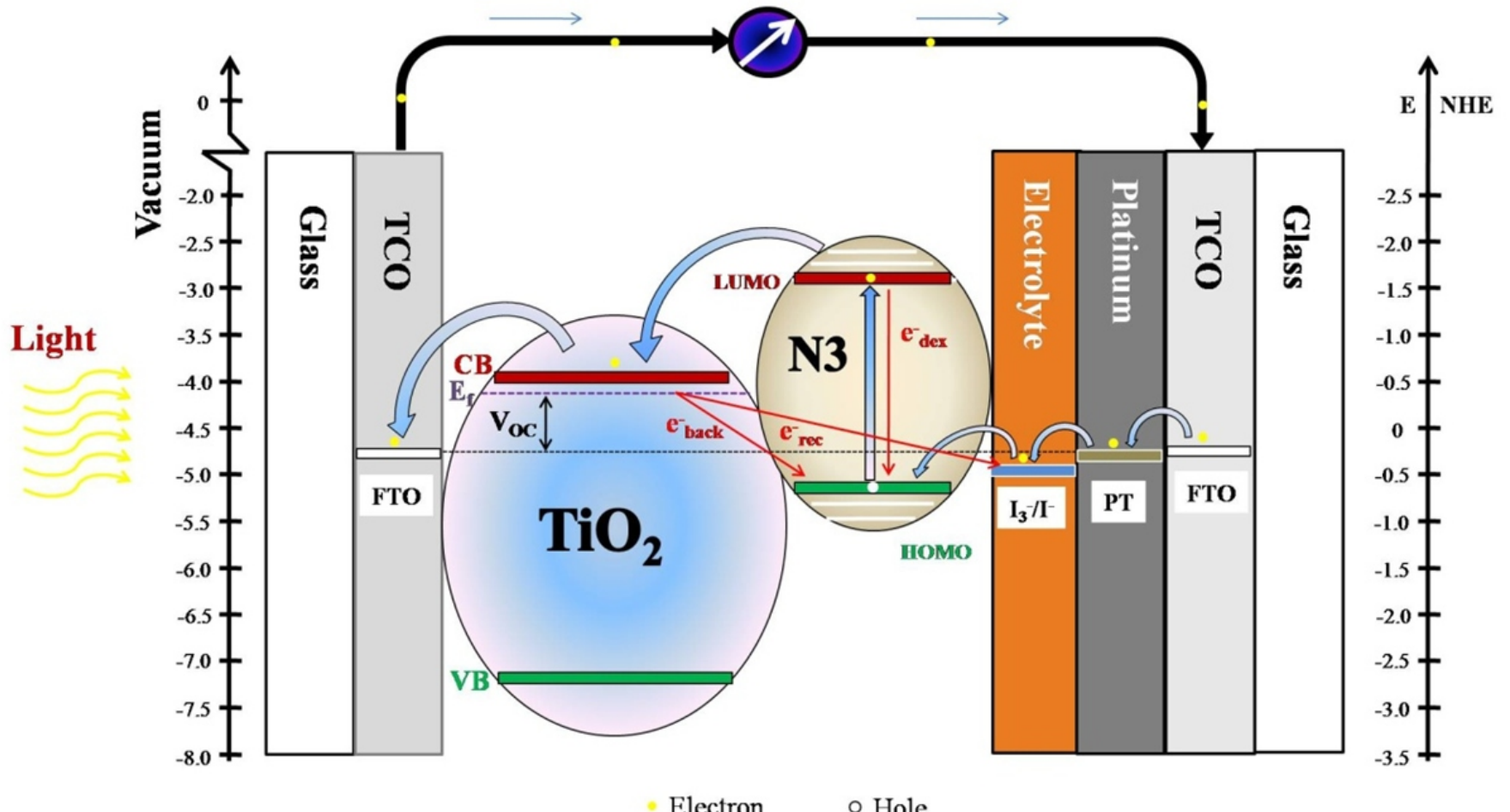

Fig. 2 The relative energy components as well the mechanism happened on interface of $\mathrm{N} 3$ dye sensitizer when artificial light is irradiate. $\left(\mathrm{E}_{\mathrm{f}}=\right.$ Fermi level, $\mathrm{e}_{\mathrm{dex}}^{-}=$de-excited electron, $\mathrm{e}_{\text {back }}^{-}$back electron transfer, $\mathrm{e}_{\mathrm{rec}}^{-}=$recombination )

The photoelectrode shows closely connected porous nature which is helpful for maximum dye loading which will help to enhance light harvesting efficiency and photocurrent density. As shown in Fig. 1 one peak is found around $320 \mathrm{~nm}$, second peak is observed at $420 \mathrm{~nm}$ and third peak is observed as $545 \mathrm{~nm}$. Baxter reported that dyes with higher molar absorption gives thinner nanoparticle film which reduces the dark current and increases the photovoltage. ${ }^{27}$ The two broad bands in the visible region at 419 and $547 \mathrm{~nm}$ of N3 are assigned to metal-to-ligand charge transfer. The bands in the UV region at $322 \mathrm{~nm}$ are assigned to intra-ligand charge transfer transitions. ${ }^{28}$

\section{Photoelectrochemical properties}

\section{$J-V$ characteristics}

The relative energies of these components as well the mechanism happened on interface of $\mathrm{N} 3$ dye sensitizer when artificial light is irradiated is explained in Fig. 2. when light is irradiated on the cell photon absorption by $\mathrm{N} 3$ dye molecule generates an excited state with sufficient potential to inject an electron into the conduction band of $\mathrm{TiO}_{2}$. The now oxidized dye is reduced via electron transfer from the mediator, effectively regenerating the ground state dye. Now, the electron in the metal oxide enters the external circuit to do useful work and then reduces the oxidized mediator at the counter electrode. In 

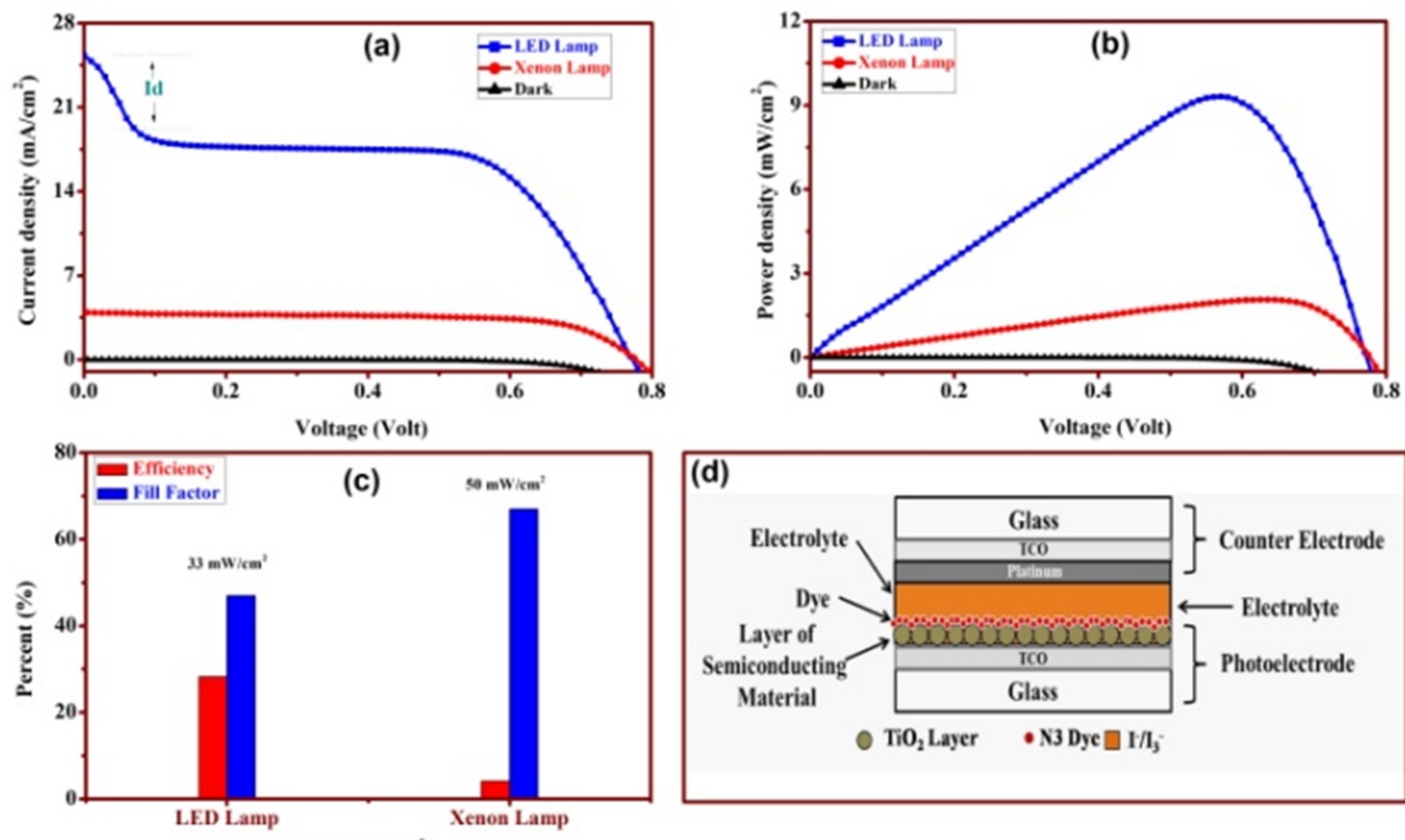

Intensity $\left(\mathrm{mW} / \mathrm{cm}^{2}\right)$

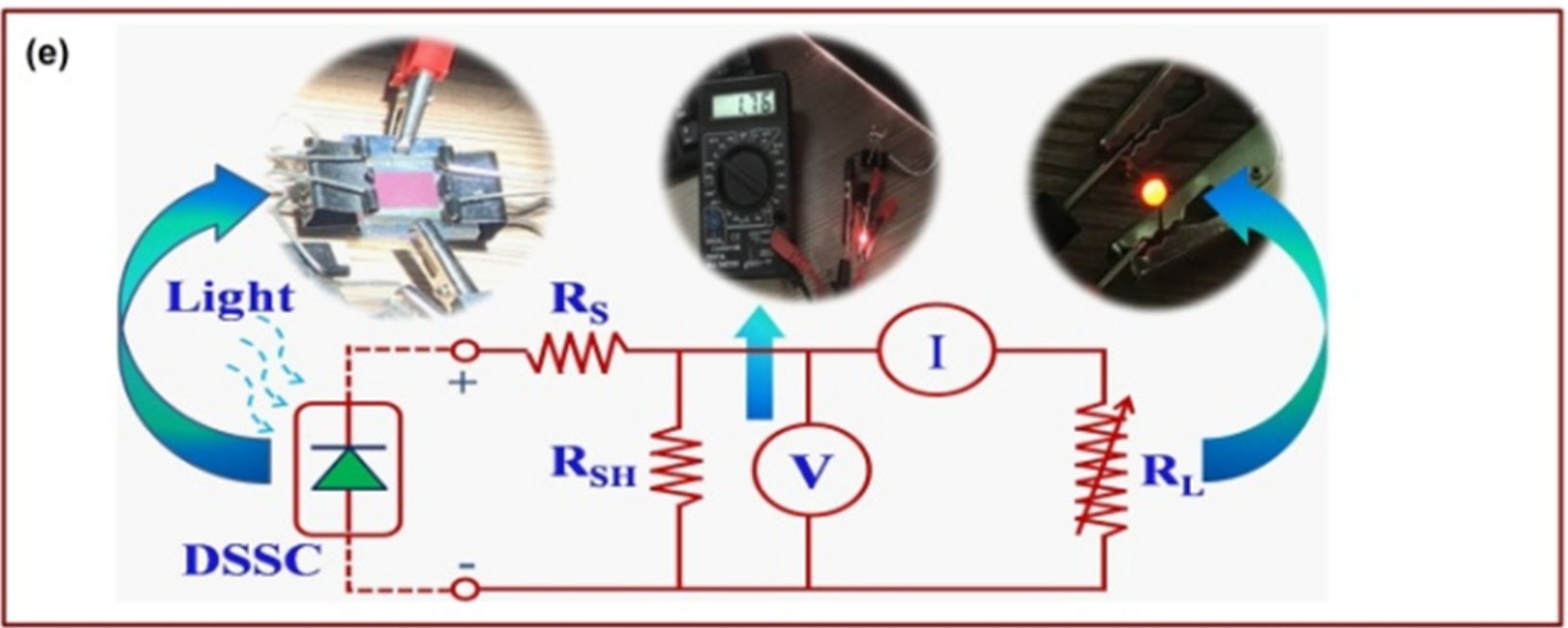

Fig. 3 (a) Plot of current density as a function of voltage, (b) Power density versus voltage under dark and different artificial illumination sources, (c) camparative plot of Efficiency and fill factor of fabricated device Vs two different light intensities, (d) schematic diagram of layer by layer fabricated DSSC and (e) circuit diagram of solar cell testing with glowing LED using serially connected three dye sensitised solar cell.

addition to the above mechanism there are some condition which reduces the performance DSSC such as before entering the external circuit, the injected electron can get reversely transferred to the oxidized dye via back electron transfer and electrolyte via recombination. ${ }^{29}$

Fig. 3(a) shows the plot of current density as a function of voltage for N3 sensitized titania DSSC under different illumination conditions viz; Xenon lamp $\left(50 \mathrm{~mW} / \mathrm{cm}^{2}\right)$, LED lamp $\left(33 \mathrm{~mW} / \mathrm{cm}^{2}\right)$ and under the dark condition. As seen, our N3 sensitized titania DSSCs has higher current density under the illumination of LED lamp in comparison with illumination under the xenon lamps. The increase in current density suggests increase in light harvesting capacity of N3 sensitized titania DSSCs under the illumination of LED lamp due to good match between emission spectra of LED lamp with absorption spectra of dye, both of them mainly span of range of visible wavelengths only. Photoelectrodes tested under artificial light exhibited $I_{d}$ values around $4 \mathrm{~mA} / \mathrm{cm}^{2} . I_{d}$ is the anodic spike shown in Fig. 3(a), observed enhancement in current due to the recombination of the photo generated charge carriers at the electrode/electrolyte interface when it was illuminated to light. $^{30}$ The highest efficiency $(28.21 \%)$ has been obtained for N3 sensitized titania DSSC illuminated with LED lamp and the corresponding fill factor was $47 \%$ as shown in Table 1 . The enhancement in the efficiency under artificial lighting indicates improvement in performance of DSSC under the artificial lighting compare to conventional solar simulator source. This is because the 
spectral distribution of artificial lighting spectrum in the region of 400 to $500 \mathrm{~nm}$ shown in Fig. 1, overlaps more favorably with absorption spectrum of N3 dye than solar simulator source. Fill factor observed for LED and xenon illumination is $47 \%$ and $67 \%$ respectively. Fill factor of LED is lower than xenon lamp illumination. In LED light we found current density $25.35 \mathrm{~mA} / \mathrm{cm}^{2}$ with $4 \mathrm{~mA} / \mathrm{cm}^{2} \mathrm{I}_{\mathrm{d}}$ value. This fast current decrease affects the fill factor of the cell under LED illumination. Under xenon illumination, no $I_{d}$ value is observed. The stable current density is the reason for higher fill factor in xenon than LED illumination. Photovoltaic parameters such as efficiency, fill factor, current density and voltage of a cell measured under the irradiance of Xenon lamp and LED lamp supporting information Fig. S3. These results indicate reduction in loss mechanism at reduced intensities of light source. Photovoltaic parameters such as efficiency, fill factor, current density and voltage of 11 DSSCs having PEC $>25 \%$ under the irradiance of Xenon lamp and LED lamp. Results are quoted after 11 experiments supporting information Fig. S4. It has been observed that when reducing the illumination intensity, the power conversion efficiency increases from 4.13 to $28.21 \%$. It is observed that current density increases from 3.93 to $25.35 \mathrm{~mA} / \mathrm{cm}^{2}$. The fill factor decreases with increase in light illumination from 67 to $47 \%$. Gratzel group ${ }^{31}$ reported DSSC up to $13.1 \%$ at $0.5 \mathrm{sun}$. Wang et. al $\hat{l}^{2}$ reported $20 \%$ efficiency under indoor measurement. Teran ${ }^{33}$ reported power conversion efficiency for AlGaAs of $21.1 \%$ which was highest for indoor lightning. Feldt et.al ${ }^{34}$ repoted at $25 \mathrm{~mW} / \mathrm{m}^{2}$ max power of 10.7 $\mu \mathrm{W} / \mathrm{cm}^{2}$. Barber et.al ${ }^{35}$ reported $19 \%$ efficiency for $\mathrm{TiO}_{2}$ sensitized N3 dye at $38 \mathrm{~mW} / \mathrm{cm}^{2}$. According to Green et. al $^{36}$ light emitted by an ideal cell to that by a blackbody Shockley and Quesser showed that the performance of a standard cell was limited to $31 \%$ efficiency. According to Hagfeldt $e t . a l^{37}$ and Zhang et.al ${ }^{38}$, the increase of $\mathrm{I}_{\mathrm{SC}}$ was explained by positive shift of the conduction band under UV illumination. Fig. 3(b) is the variation of power density as a function of voltage for N3 sensitized titania DSSC under different illumination conditions. The maximum power density has been observed for LED lamp $\left(9.30 \mathrm{~mW} / \mathrm{cm}^{2}\right)$ followed by xenon lamp $\left(2.13 \mathrm{~mW} / \mathrm{cm}^{2}\right)$. Fig. 3 (c) shows the comparative representation of photovoltaic parameters such as efficiency and fill factor with respect to incident artificial LED and xenon lamp light sources. Fig. 3(d) shows schematic diagram of layer by layer fabricated N3 sensitized Titania photoanode with platinum as counter and polyiodide as liquid electrolyte. Fig. 3(e) shows circuit diagram of solar cell testing with glowing LED using serially connected three dye sensitized solar cells. The three serially connected devices were illuminated under xenon lamp to glow red colored LED tested for long time duration. The maximum required voltage to glow LED is $2 \mathrm{~V}$ and generated voltage by single cell is $0.7 \mathrm{~V}$. These three single cell were connected serially to glow LED. Overall good performance of Titania based DSSCs is observed. This may be due to porous morphology of $\mathrm{TiO}_{2}$ film sensitized with dye molecules, more electron lifetime, smooth charge transfer process of excited electron from HOMO to LUMO of dye molecule, LUMO to conduction band of $\mathrm{TiO}_{2}$ then towards external circuit through FTO, platinum coated FTO counter electrode and electrolyte respectively. The suitability of device for dye sensitized solar cell application is observed.

DSC shows better performance in interior lightning because it is able to sustain performance even at low incident power densities as it is good match between the emission spectra of LEDs with the absorption spectrum of the dye, as both of them mainly span the range of visible wavelengths only.

\section{Electrochemical Impedance Spectroscopy}

Electro Impedance spectroscopy carried out in $1 \mathrm{MHz}$ to $0.1 \mathrm{~Hz}$ frequency range with $-0.8 \mathrm{~V}$ constant applied potential. Fig. 4 (a) shows the bode plot with characteristic frequency peak in the middle frequency range. LED lamp shows shift towards higher frequency peak compared to xenon lamp and dark. The observed shift in frequency is mentioned in Table 2. Any shift of peak from higher frequency to lower frequency reveals a more rapid electron transport process. The mean electron life time calculated from the relation $\tau_{\text {eff }}=\frac{1}{2 \pi f_{\max }}$, where, $\mathrm{f}_{\max }$ is the frequency at the top of the intermediate frequency arc. ${ }^{39}$ The electron lifetime observed under dark condition, Xenon lamp and LED lamp is observed to be $7.39,4.66$ and 2.52 mili second respectively. When light is incident on cell, the electron are generated and current flows through the external circuit, which reduces the charge recombination resistance and this reduces the electron lifetime. Similar trends in EIS result in dark and light was observed by Wu-Qiang et.al. ${ }^{40}$.

The EIS study is carried out to determine electron transport and recombination resistance. The experimental impedance data, determined using nyquist plot is shown in Fig. 4(b). the experimental impedance data given by nyquist plots in Figure were fitted to an equivalent circuit based on the diffusion-recombination model. ${ }^{41}$ The series resistance of
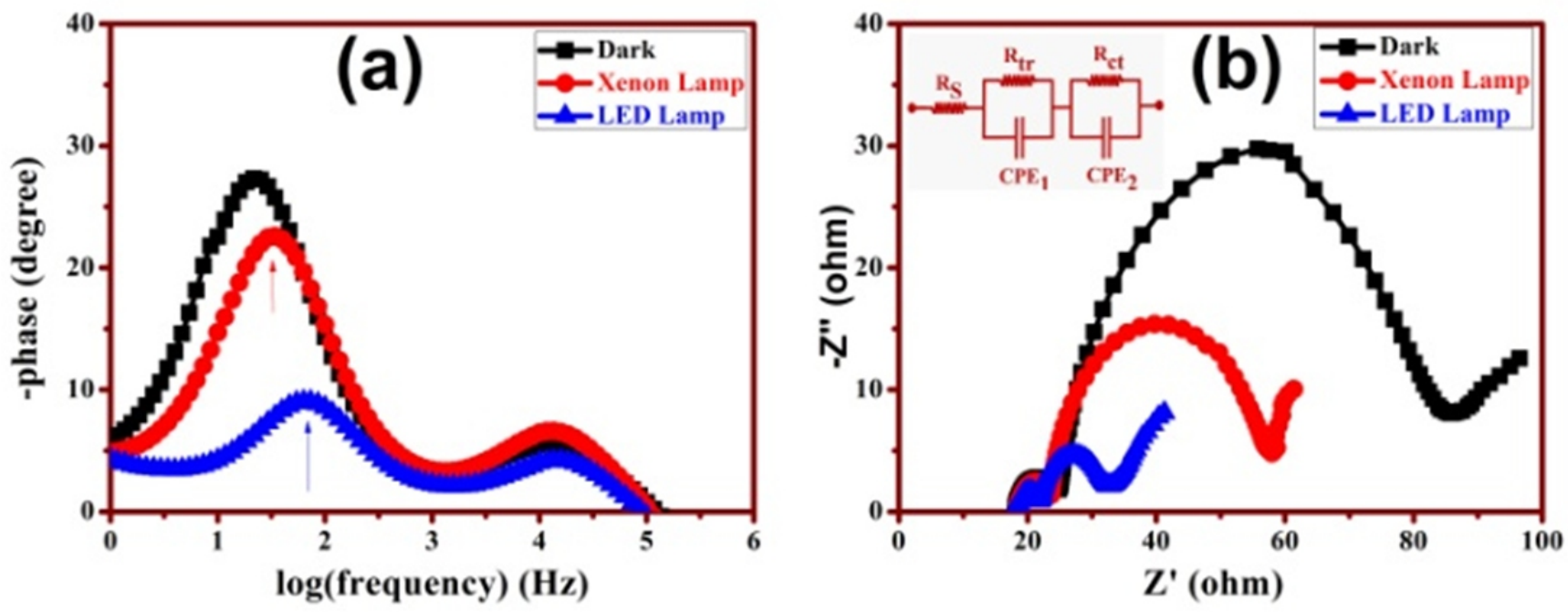

Fig. 4 Electrochemical Impedance spectra (a) Bode plot and (b) Nyquist plot with equivalent circuit of N3 sensitized titania DSSCs under dark and different artificial illumination sources. 
Table 1 Typical solar cell performance parameters, Cell Area $0.18 \mathrm{~cm}^{2}$.

\begin{tabular}{|c|c|c|c|c|c|c|}
\hline \multirow{2}{*}{ Lamp } & \multicolumn{2}{|c|}{ Illumination Light Intensity } & \multirow{2}{*}{$\begin{array}{l}\mathbf{V}_{\text {oc }} \\
\text { (V) }\end{array}$} & \multirow{2}{*}{$\begin{array}{c}\mathrm{J}_{\mathrm{sc}} \\
\left(\mathrm{mA} / \mathrm{cm}^{2}\right)\end{array}$} & \multirow{2}{*}{$\begin{array}{l}\text { FF } \\
(\%)\end{array}$} & \multirow{2}{*}{$\begin{array}{c}\eta \\
(\%)\end{array}$} \\
\hline & $\left(\mathrm{mW} / \mathrm{cm}^{2}\right)$ & $\operatorname{Lux}\left(\times 10^{3}\right)$ & & & & \\
\hline LED & 33 & 225 & 0.76 & 25.35 & 47 & 28.21 \\
\hline Xenon & 50 & 342 & 0.77 & 03.93 & 67 & 4.12 \\
\hline
\end{tabular}

Table 2 Electron transport properties of fabricated cell.

\begin{tabular}{|c|c|c|c|c|c|c|c|c|c|c|}
\hline \multirow{7}{*}{$\begin{array}{c}\text { Sample Under } \\
\text { Light } \\
\text { Illumination } \\
\text { Condition }\end{array}$} & $\begin{array}{l}\mathbf{R}_{\mathrm{tr}} \\
(\Omega)\end{array}$ & $\begin{array}{l}\mathbf{R}_{\mathrm{ct}} \\
(\Omega)\end{array}$ & $\begin{array}{c}\text { f } \\
(\mathrm{Hz})\end{array}$ & $\frac{\mathbf{R}_{\mathrm{tr}}}{\mathbf{R}_{\mathrm{ct}}}$ & $\mathbf{L}_{n}(\mu \mathbf{m})$ & $\eta_{\text {cc }}(\%)$ & $\mathbf{t}_{\mathrm{eff}}(\mathrm{msec})$ & $t_{d}(m s e c)$ & $\begin{array}{c}D_{\text {eff }} \\
\left(\mathrm{cm}^{2} \sec ^{-1}\right)\end{array}$ & $\mathbf{L}_{\text {eff }}(\boldsymbol{\mu m})$ \\
\hline & Electron & Charge & & & & & & & Effective & \\
\hline & Transfer & Transfer & & & & Charge & Mean & & Electron & \\
\hline & Resistance & Resistance & Frequency & & Diffusion & Collection & Electron & Electron & Diffusion & Electron \\
\hline & ff & 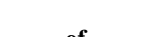 & & & Length & & & Diffusion & Crefer & Diffusion \\
\hline & OI & 01 & & & & Emerency & Liledine & Time & coencientit & Length \\
\hline & Counter & Photoanode & & & & & & & $(\mathbf{x 1 0})$ & \\
\hline Dark & 6.8 & 62 & 21.54 & 9.1 & 18.12 & 90.12 & 7.39 & 0.81 & 4.4 & 18.12 \\
\hline Xenon Lamp & 5.4 & 35 & 34.15 & 6.4 & 15.28 & 86.63 & 4.66 & 0.72 & 5.0 & 15.28 \\
\hline LED Lamp & 3.7 & 11 & 63.1 & 2.9 & 10.35 & 74.83 & 2.52 & 0.85 & 4.2 & 10.35 \\
\hline
\end{tabular}

solar cell calculated from nyquist plot is $\mathrm{Rs}=\sim 18$. The impedance spectra consist of three semicircles. The elements related to interface of counter electrode and electrolyte include the electron transport resistance $R_{t r}$, the charge transfer resistance $R_{c t}$ which is related to the recombination of electrons at $\mathrm{TiO}_{2} /$ dye/electrolyte interface. This EIS equivalent circuit fitted parameters $R_{t r}$ and $R_{c t}$ can be used to calculate the parameters such as diffusion length $\left(\mathrm{L}_{\mathrm{n}}\right)$, charge collection efficiency $\left(\eta_{c}\right)$, effective electron diffusion coefficient $\left(D_{\text {eff }}\right)$, effective electron diffusion length $\left(\mathrm{L}_{\mathrm{eff}}\right)$, which is useful to study the electron transport properties of solar cell. We have obtained the experimental impedance data at various light intensities. Usually, the semicircle in lowest frequency range assigns the electrolyte interface by Warburg diffusion process of I and $I_{3}^{-}{ }^{42}$

With the help of EIS nyquist plot, the diffusion length is calculated using formula $\ln =\sqrt{\frac{\mathrm{R}_{\mathrm{ct}}}{\mathrm{R}_{\mathrm{tr}}}}{ }^{33}$ Further effective electron diffusion co-efficient in the photoanode is given by $\mathrm{D}_{\mathrm{eff}}=\frac{\mathrm{R}_{\mathrm{ct}}}{\mathrm{R}_{\mathrm{tr}}} * \frac{1^{2}}{\tau_{\text {eff }}},{ }^{42}$ where 1 is the thickness of $\mathrm{TiO}_{2}$ film. Charge collection efficiency is calculated using $\eta_{\mathrm{cc}}=1-\frac{\mathrm{R}_{\mathrm{tr}}}{\mathrm{R}_{\mathrm{ct}}} \cdot{ }^{44}$ Effective electron diffusion length calculated using $\mathrm{L}_{\text {eff }}=\sqrt{\mathrm{D}_{\text {eff }} * \tau_{\text {eff }}} .45$ Effective electron diffusion length calculated using $\tau_{\mathrm{D}}=\tau_{\mathrm{eff}} * \frac{\mathrm{R}_{\mathrm{tr}}}{\mathrm{R}_{\mathrm{ct}}} \cdot{ }^{46}$ The calculated values are given in table no 2 .

\section{Stability Test}

The open circuit voltage decay and photocurrent stability of N3 sensitized titania DSSCs analyzed under the different light sources for the short time period (1000 s). The measurements were carried out for un-sealed DSSC device. Fig. 5 shows the stability test for N3 sensitized titania DSSC with variation of current density and voltage of N3 sensitized titania DSSC as a function of time. As seen when light source is $\mathrm{ON}$, both voltage and current density of DSSC suddenly enhances. Photoanodes exhibited $I_{d}$ values around $4 \mathrm{~mA}$ and the observed anodic enhancement in current is due to the recombination of the photo generated charge carriers at the electrode/electrolyte interface when it was illuminated to light. ${ }^{28}$ The rise in voltage and current density is maximum for DSSC exposed to LED lamp followed by exposure to xenon lamp. It is interesting to note that the current density and voltage remain constant when the light sources are ON suggesting excellent stability of N3 sensitized titania DSSC for indoor lighting. We expect high rise in current density and voltage for sealed N3 sensitized titania DSSCs because sealing enhances the lifetime of dye and the electrolyte.

\section{Conclusion}

We have studied the indoor performance of N3 sensitized titania DSSCs under artificial lighting. It is observed that there is substantial improvement in the performance of solar cell efficiency. In standard AM1.5G $50 \mathrm{~mW} / \mathrm{cm}^{2}$ sunlight, the PCE reaches above $3 \%$. Remarkably, under indoor illumination of $33 \mathrm{~mW} / \mathrm{cm}^{2}$ the maximum PCE of this new DSSC design is $28.21 \%$, which results in a power output of $9.31 \mathrm{~mW} / \mathrm{cm}^{2}$. This power is sufficient to establish the independent operation of a wide range of electronic devices in the indoor environment with reasonable solar cell size as low power electronic devices typically consume $100 \mathrm{~W}$ in sleep mode. The electron transport properties were studied using electrochemical impedance spectroscopy, which supports JV characteristics. The present 

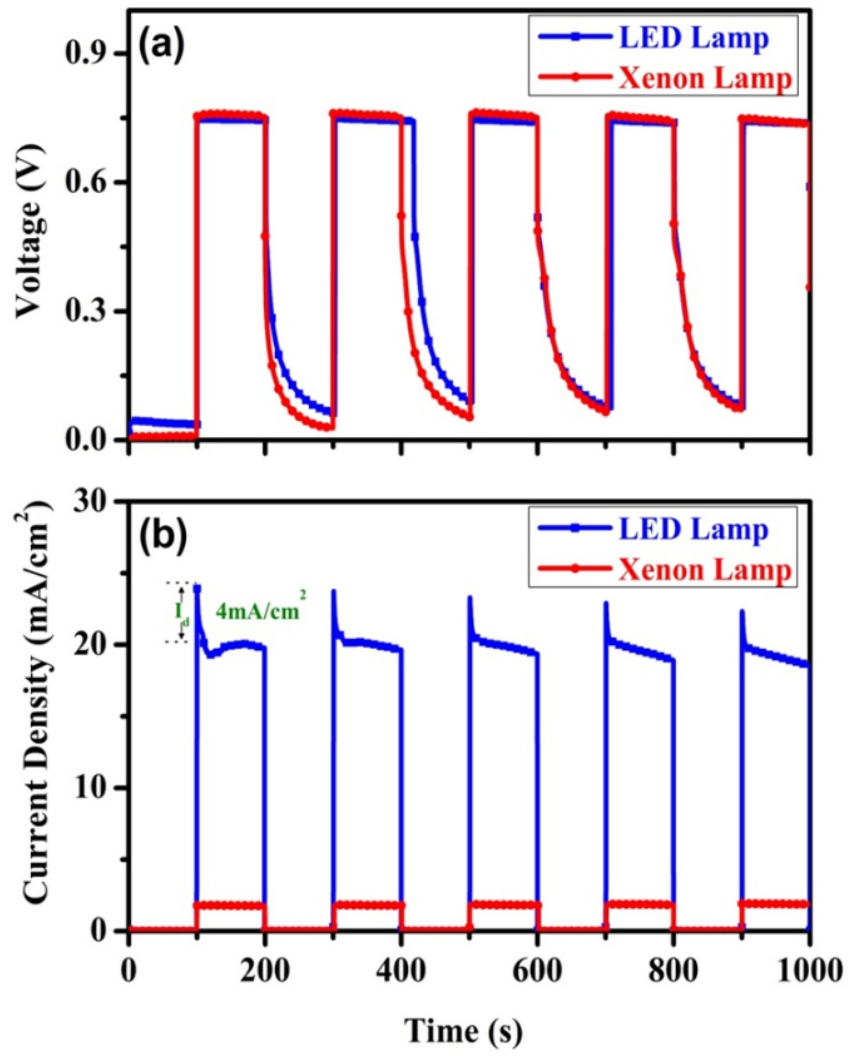

Fig. 5 Stability test for N3 sensitized titania DSSC (a) Change in open circuit voltage and (b) Change in current density under the illumination of LED Lamp and xenon lamp.

study suggests that the N3 sensitized titania DSSCs are ideally suited for artificial light applications and proved that an LED can glow with the help of this DSSC. We expect our results to have a major practical impact on low power electronic devices as harvesting the artificial light energy for power electronic devices require low electric power for their autonomous operation. Overall, our findings suggests that the obtained high efficiency N3 sensitized titania DSSCs under artificial lighting have a good potential application for low power electronic devices for their autonomous operation.

\section{Author contributions}

HMP conceived the work and CVJ, VSK and HMP designed the experiments and wrote the manuscript. CVJ and VSK fabricated and characterized the solar cells: assembled the devices. HMP and SRJ coordinated the work. CVJ and VSK equally contributed the work.

\section{Notes}

The authors declare no competing financial interest.

\section{Acknowledgements}

We acknowledge the Board of College and University Development ,Savitribai Phule Pune University Pune, India for financial support . VSK and CVJ are thankful to Dr. Rajendra Prasad MB, Dr. Prashant K. Baviskar, Dr. Vikram P. Bhalekar, Ms. Parvin S. Tamboli, Mr. Ravi V. Ingle, Mr. Niyamat I. Beedri for fruitful discussion.

\section{References}

1. R. Gottschalg, J. A. Del Cueto, T. R. Betts and D. G. Infield, Conference Record of the IEEE Photovoltaic Specialists Conference 2005, 1484-1487.

2. C. N. Jardine, G. J. Conibeer and K. Lane, Proceedings of the 17th European Photovoltaic Solar Energy Conference 2001, 724-727.

3. M. Pierro, F. Bucci and C. Cornaro, Prog. Photovolt: Res. Appl. 2014, 23, 443-461.

4. C. Cornaro, Prog. Photovolt: Res. Appl. 2015, 23, 215-225.

5. J. Bisquert, ChemPhySchem. 2011, 12, 1633-1636.

6. C. Radue, E. E. Van Dyk and E.Q. Macabebe, Thin Solid Films, 2009, 517, 2383-2385.

7. J. A. Hauch, P. Schilinsky, S. A. Choulis, R. Childers, M. Biele and C.J. Brabec, Sol. Energ. Mat. Sol. C, 2008, 92, 727-731.

8. Q. Jiang, L. Wang, C. Yan, C. Liu and Z. Guo, ES energy Environ., 2018, 1, 64-68.

9. P. Panneerselvam, V. Murugadoss, V. Elayappan, N. Lu, Z. Guo and S. Angaiah, ES energy Environ., 2018, 1, 99-105.

10. A. Reale, L. Cinà, A. Malatesta, R. De Marco, T. M. Brown and A. Di Carlo, Energy Technol-ger, 2014, 2, 531-541.

11. V.Zardetto, G. Mincuzzi, F. De Rossi, F. Di Giacomo, A. Reale, A. Di Carlo and T. M. Brown, Appl. Energ., 2014, 113, 1155-1161.

12. C. Lee, R. Y. Lin, L. Lin, C. Li, T. Chu, S. Sun, J. T. Lin and K. Ho, RSC Advances, 2015, 5, 23810-23825.

13. O. O. Ogunsolu, J. C. Wang and K. ACS Appl. Mater. Inter., 2015, 7, 27730-27734.

14. K. Kalyanasundaram, J. Photoch Photobio C, 2003, 4(2):145-153.

15. R. Sakamoto, S. Katagiri, H. Maeda, Y. Nishimori, S. Miyashita and H. Nishihara, J. Am. Chem. Soc., 2015, 137, 734-741.

16. I. Mathews, P. J. King, F. Stafford and R. Frizzell, IEEE Journal of Photovoltaics, 2016, 6, 230-235.

17. B. P. Lechêne, M. Cowell, A. Pierre, J. W. Evans, P. K. Wright and A. C. Arias, Nano Energy, 2016, 26, 631-640.

18. F. De Rossi, T. Pontecorvo and T. M. Brown, Appl Energ, 2015, 156 413-422.

19. C. P. Lee, C. Lin, T. Wei, M. Tsai, Y. Meng, C. Li, K. Ho, C. Wu, S. Lau and J. He, Nano Energy, 2015, 18, 109-117.

20. F. D. Rossi, T. M. Brown and T. Pontecorvo, EEEIC 2015-Conference Proceedings 2015, 2100-2103.

21. H. K. H. Lee, Z. Li, J. R. Durrant and W. C. Tsoi, Appl. Phys. Lett., 2016, 108, 253301-253305.

22. M. Freitag, J. Teuscher, Y. Saygili, X. Zhang, F. Giordano, P. Liska, J. Hua, S. M. Zakeeruddin, J. Moser, M. Grätzel and A. Hagfeldt, Nat. Photonics., 2017, 11, 372-378.

23. S. S. Khadtare, A. P. Ware and S. Salunke-gawali, RSC Advances, 2015, 5, 17647-17652.

24. C. Law, L. Miseikis, S. Dimitrov, P. Shakya-Tuladhar, X. Li, P. R. F. Barnes, J. Durrant and B.C.O'Regan, Adv. Mater., 2014, 26, 6268-6273.

25. Y. Li, N. J. Grabham, S. P. Beeby and M. Tudor, Sol. Energy, 2015, 111, 21-29.

26. F. D. Rossi, T. Pontecorvo and T. M. Brown, Appl Energ, 2015, 156, 413-422.

27. J. B. Baxter, J. Vac. Sci. Technol. A, 2012, 30, 020801-19.

28. U. Mehmood, I. A. Hussein, K. Harrabi, M. B. Mekki, S. Ahmed and N. Tabet, Sol. Energ. Mat. Sol. C, 2015, 140, 174-179.

29. J. C. Wang, S. P. Hill, T. Dilbeck, O. O. Ogunsolu, T. Banerjee and K. Hanson, Chem. Soc. Rev, 2018, 47, $104-148$.

30. A. Subramanian, E. Gracia-Espino and A. Annamalai, Appl. Surf. Sci., 2018, 427, 1203-1212.

31. S. Mathew, A. Yella, P. Gao, R.H. Baker, B. F. E. Curchod, N. A. Astani, I. Tavernelli, U. Rothlisberger, M.K. Nazeeruddin and M. Gratzel, Nat. Chem., 2014, 6, 242-247.

32. L. Wang, B. Conrad, A. Soeriyadi, M. Diaz, X. Zhao, D. Li, A. Lochtefeld, A. Gerger, C. Ebert, I. Perez-Wurfl and A. Barnett, Proceedings of the 42nd IEEE PVSC, 2015, 1.

33. A. S. Teran, J. Wong, W. Lim, G. Kim, Y. Lee, D. Blaauw and J. D. Phillips, IEEE Transaction. Dev., 2015, 62, 2170-2175.

34. S. M. Feldt, E. A. Gibson, E. Gabrielsson, L. Sun, G. Boschloo and A. Hagfeldt, J. Am. Chem. Soc., 2010, 132, 16714-24.

35. G. D. Barber, P. G. Hoertz, S. A. Lee, N. M. Abrams, J. Mikulca, T. E. Mallouk, P. Liska, S. M. Zakeeruddin, M. Gratzel, A. Ho-Baillie and M. A. 
Green, J. Phys. Chem. Lett., 2011, 2, 581-585.

36. M. A. Green, Physi. E, 2002, 14, 65-70.

37. A. Hagfeldt, U. Bjolrksten and M. Gra1tzel, J. Phys. Chem., 1996, 100, 8045-8048.

38. B. D. Zhang, T. Yoshida, T. Oekermann, K. Furuta and H. Minoura, $A d v$. Funct. Mater., 2006, 16, 1228-1234.

39. J. H. Kim, K. J. Moon, J. M. Kim, D. Lee and S. H. Kim, Sol. Energy, 2015, 113, 251-257.

40. W. Q. Wu, Y. F. Xu, C.Y. Su and D. B. Kuang, Energy Environ. Sci., 2014, 7, 644-649.
41. J. Bisquert, J. Phys. Chem. B, 2002, 106, 325-333.

42. M. Adachi, M. Sakamoto, J. Jiu, Y. Ogata and S. Isoda, J. Phys. Chem. B, 2006, 110, 13872-13880.

43. H. X. Wang and L. A. A Peter, J. Phys. Chem. C, 2009, 113, 18125-18133.

44. Q. Wang, J. E. Moser and M. Grätzel, J. Phys. Chem. B, 2005, 109, 14945-14953.

45. H. K. Dunn, P. O. Westin, D. R. Sta, L. M. Peter, A. B. Walker, G. Boschloo and A. Hagfeldt, J. Phys. Chem. C, 2011, 115, 13932-13937.

46. W. Chang, C. Lee, W. Yu and C. Lin, Nanoscale Res. Lett., 2012, 7, 1. 